\title{
Treatment persistence of subcutaneous TNF inhibitors among Australian patients with immune-mediated rheumatic disease (IMRD)
}

This article was published in the following Dove Press journal: Open Access Rheumatology: Research and Reviews

\author{
Mustafa Acar' \\ Prabhjot Juneja ${ }^{2}$ \\ Malcolm Handel' \\ 'Janssen-Cilag Pty Ltd, Sydney, NSW, \\ Australia; ${ }^{2}$ Prospection Pty Ltd., \\ Sydney, NSW, Australia
}

\begin{abstract}
Introduction: To describe the persistence of treatment with subcutaneous tumor necrosis factor inhibitors (TNFi) adalimumab, etanercept, and golimumab in immune-mediated rheumatic disease (rheumatoid arthritis, psoriatic arthritis, and ankylosing spondylitis) by treatment sequence (first-line treatment, second-line or further lines of treatment).

Methods: A retrospective cohort analysis was conducted using the Australian Commonwealth Department of Human Services Pharmaceutical Benefits Scheme 10\% sample data from January 1, 2010, to June 30, 2016. Pharmaceutical Benefits Scheme indications were used to identify patient prescriptions for rheumatoid arthritis, psoriatic arthritis, and ankylosing spondylitis. A patient was considered persistent until a 3-month gap period where a prescription was not dispensed. The 3 -month gap interval was chosen because only $1 \%$ of all discontinuations occurred beyond this 3-month period.
\end{abstract}

Results: Data from 2,612 first-line patients were included. Treatment discontinuation among first-line patients treated with etanercept or adalimumab was not significantly different from those treated with golimumab (HR 1.10, 95\% CI 0.95-1.28, $P=0.22$; HR 1.06, 95\% CI 0.93-1.22, $P=0.39$; respectively). Among the 1,276 patients in the second-line cohort (etanercept $=41 \%$, adalimumab $=41 \%$, golimumab $=18 \%$ ) discontinuation was significantly higher for patients on etanercept compared with golimumab (HR 1.24, 95\% CI 1.03-1.50, $P=0.03$ ); but not for adalimumab compared with golimumab (HR 1.11, 95\% CI 0.91-1.34, $P=0.31$ ). In the third-line setting, treatment persistence with etanercept was longer than golimumab (HR 0.75, 95\% CI $0.59-0.96, P=0.02$ ), but there was no difference between golimumab and adalimumab. Similar findings occurred in the propensity score matched population.

Conclusion: Our study shows there is variance in real-world persistence to TNFi in patients with immune-mediated rheumatic disease by line of therapy, with the time on therapy decreasing by line. Australian persistence has been reported at lower overall rates than international evidence. Keywords: tumor necrosis factor inhibitors, arthritis, psoriatic, rheumatoid arthritis, ankylosing spondylitis, treatment persistence

\section{Introduction}

Rheumatoid arthritis (RA), psoriatic arthritis (PsA), and ankylosing spondylitis (AS) are immune-mediated rheumatic diseases (IMRDs). While the specific manifestations of each disease are different, all three of these diseases can be effectively treated using subcutaneous tumor necrosis factor inhibitors (TNFi) including adalimumab, certolizumab, etanercept, and golimumab. However, despite the benefits of TNFi, a proportion of patients will not respond to therapy or will discontinue treatment due to lack of efficacy, adverse effects or other reasons. ${ }^{1,2}$ Janssen-Cilag Pty Ltd, 66 Waterloo Rd, North Ryde, Sydney, NSW, Australia $\mathrm{Tel}+6 \mid 298153227$ Email macar@its.jnj.com 
In Australia, treatment with TNFi is reserved for patients with active disease, despite treatment with or intolerance to conventional synthetic disease-modifying antirheumatic drugs (csDMARDs). Ongoing TNFi therapy is only reimbursed for those with documented continued clinical response. Poor persistence with biologic disease-modifying anti-rheumatic drugs (bDMARDs) may reduce the therapeutic potential of these treatments, and may reduce their real-world effectiveness. ${ }^{3}$ Several groups have compared real-world persistence of $\mathrm{TNFi}$, some suggesting there are differences in persistence by the choice of $\mathrm{TNFi}^{4-8}$ and others finding no such differences. ${ }^{9,10}$ Longer persistence in patients administered golimumab compared to etanercept and adalimumab was identified in a recent systematic review. ${ }^{11}$ Persistence with bDMARDs is reportedly longer in patients with prior exposure to only csDMARDs, compared to those with prior exposure to bDMARDs. ${ }^{12,13}$

One possible reason for differences in persistence between agents is whether the agent is given in a clinic or hospital setting, or at home. ${ }^{14}$ In most countries, subcutaneous injections of TNFi are self-administered at home. Persistence rates in Japan, where subcutaneous injections are given in the clinic, are much higher than elsewhere. ${ }^{14}$ Another possible reason is the difference in diagnosis; patients with AS have been reported to have higher persistence to TNFi compared to those with RA. ${ }^{11,15}$ Alternatively, a lower administration frequency, such as with golimumab which is administered monthly, may lead to better adherence and higher persistence. ${ }^{5,6}$

The aim of this study was to describe the persistence of treatment with subcutaneous TNFi adalimumab, etanercept, and golimumab in IMRD (RA, PsA, and AS) by line of therapy in a sample of Australian patients.

\section{Materials and methods}

This retrospective cohort analysis was conducted using the Australian Commonwealth Department of Human Services Pharmaceutical Benefits Scheme (PBS) 10\% sample data, which is a national record of pharmaceutical claims containing a systematic random sample of $10 \%$ of the Medicareeligible Australian population and all of their reimbursed dispensations. The $10 \%$ sample is made available by the Australian government via data custodians for the purposes of research, with longitudinal data available for this study from January 1, 2006, to June 30, 2016. This study and publication of subsequent results were approved by the Australian Government Department of Human Services External Request Evaluation Committee (MI6894).
The PBS dataset captures community-based dispensing of prescription medicines subsidized by the Australian Government, and all molecules included in this analysis are subsidized and accessible to patients through approved pharmacies with a prescription. ${ }^{16}$ It does not capture information on medicines supplied by non-approved pharmacies or hospitals or against private prescriptions. ${ }^{16}$

\section{Patient selection}

Data were included for patients with IMRDs, as identified by PBS codes which identify both the drug molecule and disease indication. Data were analyzed for patients who initiated treatment with adalimumab, etanercept or golimumab for treatment of RA, PsA, or AS during the period January 1, 2010, until June 30, 2016. This period was selected because golimumab has been reimbursed in Australia since 2010. Patients who commenced the therapy prior to this period were excluded in order to estimate first-line use. One TNFi, certolizumab was excluded from the analysis as it was only reimbursed for AS and PsA indications in October 2014 and May 2015, respectively, and as such, data were not sufficiently mature to be included in the analysis. Some patients have been reported with multiple indications and have been included in the results of all indications they are reported against.

\section{Data}

Data analyzed included year of birth, sex, state where prescription was filled, PBS item code and drug dispensing date. From these data, variables used for analysis included age at initiation (dispensing year minus year of birth), molecule, and indication (both inferred from the PBS item code and its corresponding authority information) and line of therapy (calculated based on the order of therapy). There were no data available for the reason for discontinuation or switch. Within an Australian context, reasons for discontinuation may be associated with lack of efficacy, side effects, treatment choice or achieved remission.

\section{Statistical analysis}

Patients were considered first-line if they had not received treatment with a bDMARD or targeted synthetic DMARD (tofacitinib), including for non-immune-mediated rheumatic disease indications within the available data. If patients switched to another molecule or did not fill a prescription for 3 months, they were classed as discontinued. The 3-month interval was chosen because only $1 \%$ of all discontinuations occurred beyond this 3 -month period. The date of treatment 
discontinuation was defined as the date of the last prescription of TNFi. Treatment persistence was defined as the time (in consecutive days) from commencement of the TNFi until the date of treatment discontinuation. Treatment persistence was calculated by line of therapy and by treatment for the overall cohort using Kaplan-Meier curves. Differences in pairwise comparisons between treatment groups (etanercept and golimumab, and adalimumab and golimumab) were calculated using univariate Cox's proportional hazards models, with $P<0.05$ considered statistically significant. Hazard ratios are reported as the alternate TNFi compared to golimumab, such that values $>1.0$ favor golimumab. Golimumab was selected as the comparator group for comparison with other known evidence. ${ }^{4,17}$ All analyses were conducted using Stata version 14 for Mac (StataCorp, Texas Station, NV, USA).

\section{Propensity score matching}

As a secondary analysis, propensity score matching was used to calculate treatment persistence by accounting for differences in observed baseline characteristics that may have influenced persistence. The propensity score was the conditional probability of receiving treatment (golimumab vs other treatment) which was estimated using logistic regression. Covariates included age, gender, Australian state, initiation year, and disease indication. Propensity score matching was conducted on a 1:1 basis. The success of propensity score matching was determined by examining the propensity score distribution (density plot) in both the original and matched samples and comparing the standardized differences. These methods have been used previously when examining treatment persistence in patients with IMRD. ${ }^{17}$

\section{Sensitivity analysis}

A sensitivity analysis was conducted by indication and line of therapy, using alternate cohorts to take into account early access activities for golimumab in which patients could access treatment with golimumab prior to its availability on the PBS.

\section{Results}

Data were available for 2,612 first-line patients in the $10 \%$ PBS sample. Demographics of the included patient population are reported in Table 1 . The greatest proportion of patients had been prescribed adalimumab in first-line $(n=1,385,53 \%)$, followed by etanercept $(n=753,29 \%)$, and golimumab $(n=474,18 \%)$. In second-line, etanercept had the highest number of patients $(n=527,41 \%)$, followed by adalimumab $(n=519,41 \%)$, and golimumab $(n=230,18 \%)$. In third-line, golimumab had a slightly higher number of patients $(n=222,36 \%)$, compared with etanercept $(n=204$, $33 \%)$, and adalimumab $(\mathrm{n}=195,31 \%)$. (Table 1)

\section{Overall cohort}

In the overall cohort (all patients across IMRD diagnoses), there was no difference in treatment persistence between agents used in the first-line setting (adalimumab

Table I Demographics of included patients

\begin{tabular}{|c|c|c|c|c|}
\hline Unique patients by molecule & $\begin{array}{l}\text { Etanercept } \\
n=I, 298\end{array}$ & $\begin{array}{l}\text { Adalimumab } \\
\mathrm{n}=\mathbf{I , 9 0 I}\end{array}$ & $\begin{array}{l}\text { Golimumab } \\
\mathrm{n}=\mathbf{8 8 2}\end{array}$ & $\begin{array}{l}\text { Total } \\
\mathrm{N}=4,081\end{array}$ \\
\hline Female, n (\%) & $885(68 \%)$ & $1,200(63 \%)$ & $556(63 \%)$ & $2,64 I(65 \%)$ \\
\hline Age at initiation, years, mean $(\mathrm{Q}, \mathrm{Q} 3)$ & $53(44,63)$ & $52(42,62)$ & $52(42,62)$ & $52(42,62)$ \\
\hline \multicolumn{5}{|l|}{ State, n (\%) } \\
\hline Australian Capital Territory/New South Wales & $462(36 \%)$ & $625(33 \%)$ & $210(24 \%)$ & I,297 (32\%) \\
\hline Queensland & $206(16 \%)$ & $278(15 \%)$ & I 73 (20\%) & $657(16 \%)$ \\
\hline South Australia/Northern Territory & $104(8 \%)$ & $143(8 \%)$ & $58(7 \%)$ & $305(7 \%)$ \\
\hline Western Australia & $224(17 \%)$ & $366(19 \%)$ & $238(27 \%)$ & $828(20 \%)$ \\
\hline Victoria/Tasmania & $300(23 \%)$ & $487(26 \%)$ & $202(23 \%)$ & $989(24 \%)$ \\
\hline Missing & $2(<1 \%)$ & $2(<1 \%)$ & $\mathrm{I}(<1 \%)$ & $5(<1 \%)$ \\
\hline \multicolumn{5}{|l|}{ Indication, n (\%)* } \\
\hline Psoriatic arthritis & $235(18 \%)$ & $396(21 \%)$ & $201(23 \%)$ & $832(20 \%)$ \\
\hline Rheumatoid arthritis & $871(67 \%)$ & $1,098(58 \%)$ & $444(50 \%)$ & $2,413(59 \%)$ \\
\hline Ankylosing spondylitis & $274(21 \%)$ & $454(24 \%)$ & $275(31 \%)$ & $1,003(25 \%)$ \\
\hline \multicolumn{5}{|l|}{ Line of therapy, $\mathrm{n}(\%)^{*}$} \\
\hline First line & $753(58 \%)$ & I,385 (73\%) & $474(54 \%)$ & $2,612(54 \%)$ \\
\hline Second line & $527(41 \%)$ & $519(27 \%)$ & $230(26 \%)$ & $1,276(31 \%)$ \\
\hline Third line or more & $204(16 \%)$ & $195(10 \%)$ & $222(25 \%)$ & 621 (15\%) \\
\hline
\end{tabular}

Notes: *As explained in the patient selection section, the patient sample contains patients with more than one indication and these have been reported against all relevant indications and molecules. Percentages therefore exceed 100\% because the number of combinations of molecules, indications, and lines of therapy recorded exceed the number of unique patients. 
vs golimumab HR 1.06, 95\% CI 0.93-1.22, $P=0.39$; etanercept vs golimumab HR $1.10,95 \%$ CI $0.95-1.28, P=0.22$; Figure 1). The median treatment persistence was $16(95 \% \mathrm{CI}$ 15-19) months, 15 (95\% CI 14-17) months and 16 (95\% CI 12-21) months, for adalimumab, etanercept, and golimumab, respectively.

In the second-line setting, median treatment persistence was shorter than in the first-line setting, being 13 (95\% CI
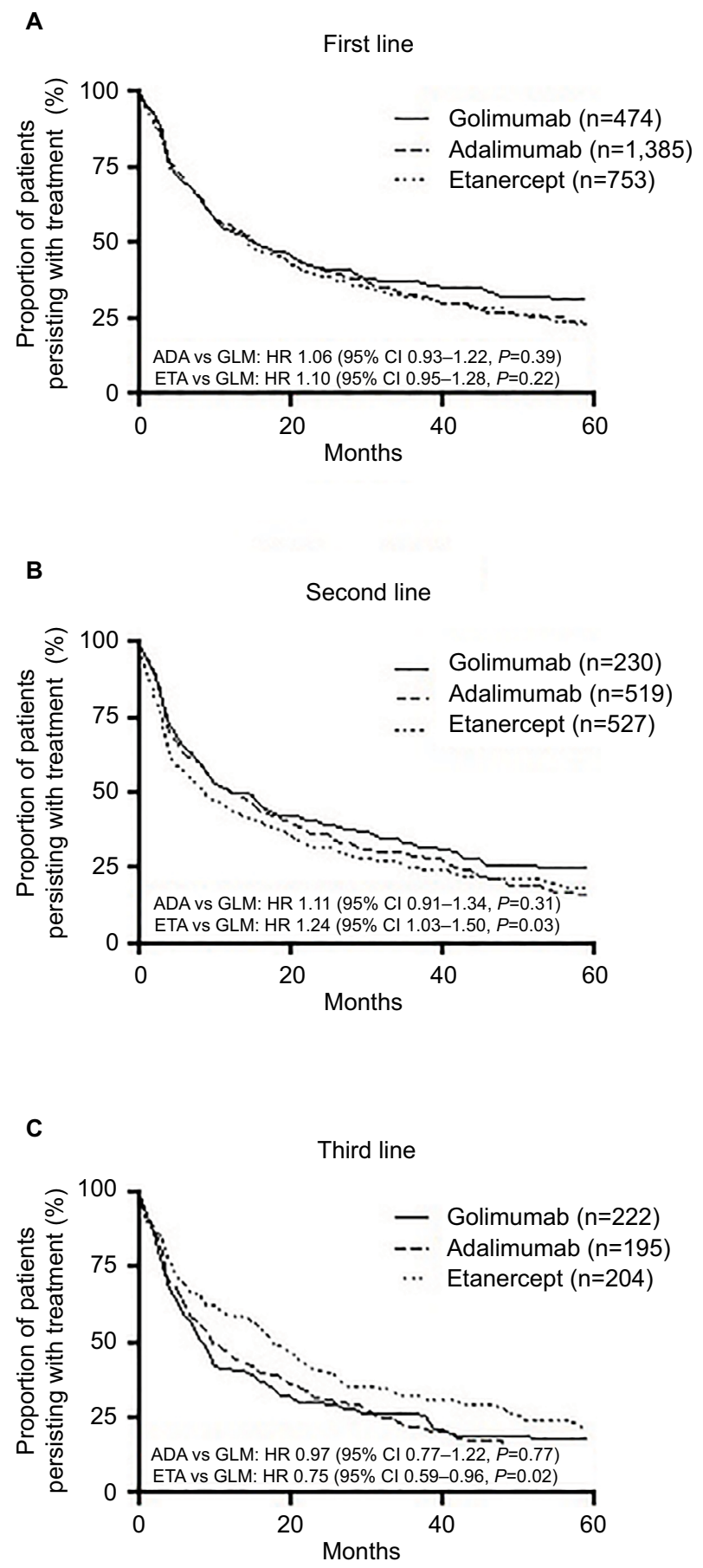

Figure I (A-C) Persistence with treatment (months) in unmatched population by treatment and line of therapy.
10-16) months, 9 (95\% CI 7-11) months, and 13 (95\% CI 10-18) months, for adalimumab, etanercept, and golimumab, respectively. Treatment persistence with etanercept as second bDMARD was significantly shorter than golimumab (HR $1.24,95 \%$ CI $1.03-1.50, P=0.03)$, whereas there was no difference in second-line persistence between adalimumab and golimumab (HR 1.11, 95\% CI 0.91-1.34, $P=0.31$; Figure 1).

In third and later lines of therapy, median treatment persistence with etanercept was longer than with other agents: being 10 (95\% CI 8-15) months, 18 (95\% CI 14-23) months, and 9 (95\% CI 7-10) months, for adalimumab, etanercept, and golimumab, respectively. Treatment persistence with etanercept as third or subsequent bDMARD was significantly longer than that with golimumab (HR 0.75, 95\% CI 0.59-0.96, $P=0.02$ ), but there was no difference between adalimumab and golimumab (HR 0.97, 95\% CI 0.77-1.22, $P=0.77$; Figure 1).

\section{Persistence by line of therapy}

For the overall cohort, persistence was higher in first-line compared to later lines. Median treatment persistence was 15 (95\% CI 14-16) months, 10 (95\% CI 9-13), and 11 (95\% CI 9-15) months from first-line, second-line, and third-line, respectively. Treatment persistence in first-line was significantly longer than second-line (HR 1.23, 95\% CI 1.12-1.34, $P \leq 0.01$ ) and significantly longer than third-line (HR 1.24, 95\% CI 1.10-1.40, $P<0.01$; Figure 2)

This finding of significantly higher first-line persistence is consistent across all indications (Figure 2).

\section{Indication specific cohorts}

\section{RA cohort}

Persistence with etanercept was significantly longer than with golimumab in the third-line setting in RA patients (HR 0.65, 95\% CI 0.48-0.90, $P=0.01)$. There were no other significant differences in persistence. Median persistence in first-line was 15 (95\% CI 13-18) months, 15 (95\% CI 11-17) months, and 15 (95\% CI 11-20) months, for adalimumab, etanercept, and golimumab, respectively. Median persistence in secondline was 10 (95\% CI 8-13) months, 9 (95\% CI 6-11) months, and 9 (95\% CI 6-16) months, and in third-line median persistence was 10 (95\% CI 7-15), 16 (95\% CI 9-19), and 6 (95\% CI 4-10) months for adalimumab, etanercept, and golimumab, respectively (Figure 2).

\section{PsA cohort}

There were no significant differences in persistence. Median persistence in first-line was 19 (95\% CI 15-27) months, 15 


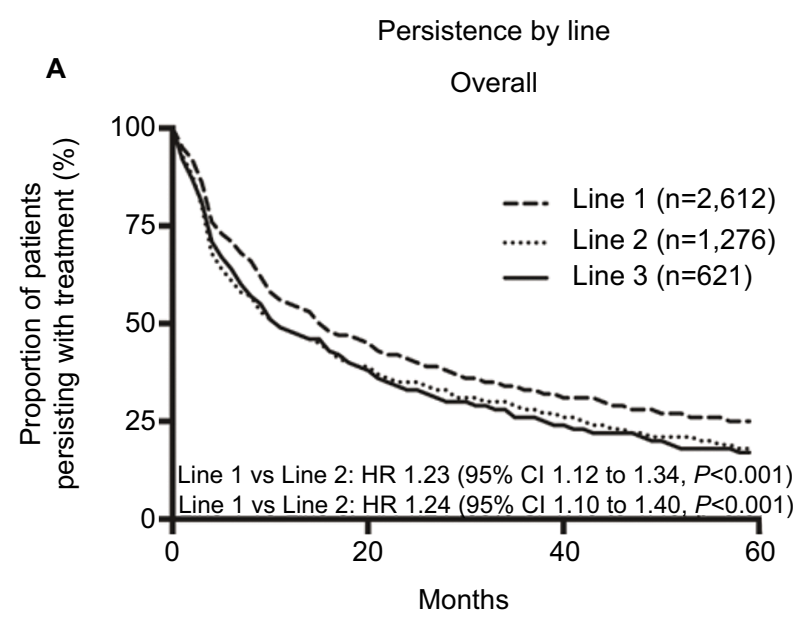

C

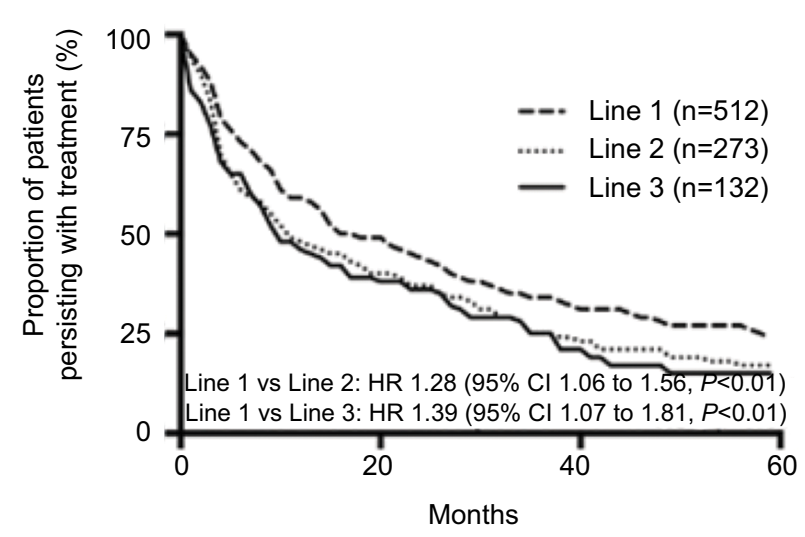

B

RA

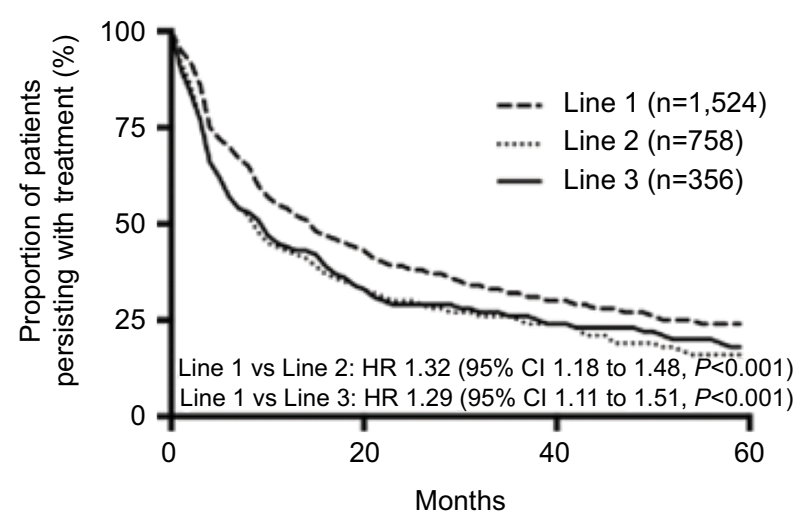

D AS

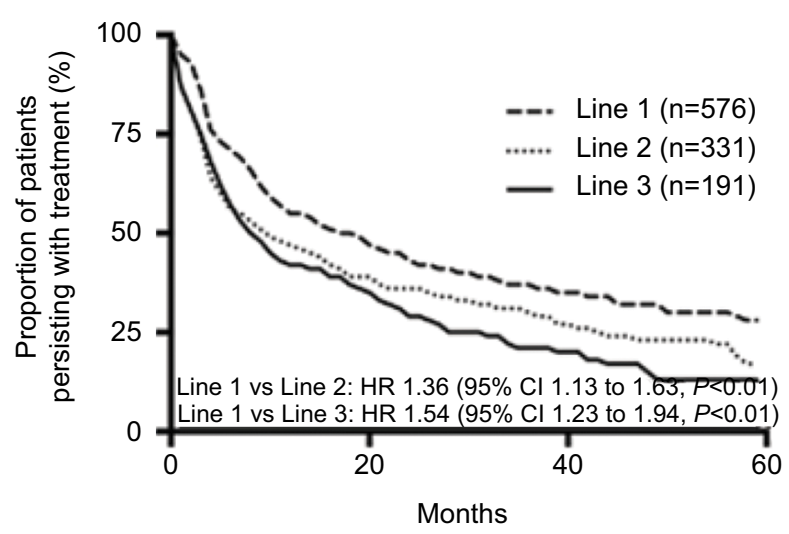

Figure 2 (A-D) Persistence with treatment (months) in unmatched population by order of therapy, overall and indication specific.

(95\% CI 11-22) months, and 21 (95\% CI 10-47) months for adalimumab, etanercept, and golimumab, respectively. Median persistence in second-line was 17 (95\% CI 10-27) months, 9 (95\% CI 5-17) months, and 11 (95\% CI 6-22) months; and in third-line was 5 (95\% CI 4-28) months, 17 (95\% CI 7-27) months, and 9 (95\% CI 7-17) months for adalimumab, etanercept, and golimumab, respectively (Figure 2).

\section{AS cohort}

Persistence was significantly shorter with etanercept compared to golimumab in the second-line setting in patients with AS (HR 1.59, 95\% CI 1.12-2.25, $P=0.01$; Figure 2). There were no other significant differences in persistence. Median persistence in first-line was 17 (95\% CI 12-22) months, 20 (95\% CI 12-30) months, and 17 (95\% CI 10-29) months for adalimumab, etanercept, and golimumab, respectively. Median persistence in second-line was 14 (95\% CI 7-22) months, 5 (95\% CI 4-9) months, and 18 (95\% CI 9-31 months); and in third line, median persistence was $8(95 \%$
CI 5-16) months, 9 (95\% CI 5-21) months, and 9 (95\% CI 6-16) months, for adalimumab, etanercept, and golimumab, respectively (Figure 2).

\section{Propensity score matched cohort}

The propensity scored matched population was well matched in terms of age, gender, Australian state, initiation year, and disease indication (Table S1). In the propensity score matched cohort, there was no difference in treatment persistence between agents used in the first-line setting (adalimumab vs golimumab HR 1.04, 95\% CI 0.88-1.23, $P=0.61$; etanercept vs golimumab HR $1.14,95 \%$ CI $0.95-1.37, P=0.15$; Figure 3). The median treatment persistence was $18(95 \% \mathrm{CI}$ 13-22) months, 15 (95\% CI 12-20) months, and 16 (95\% CI 12-21) months, for adalimumab, etanercept, and golimumab, respectively. In the second-line setting, the median treatment persistence was shorter than in the first-line setting, being adalimumab 12 (95\% CI 10-16) months, etanercept 9 (95\% CI 6-15) months, and golimumab 13 (95\% CI 10-18) or 12 

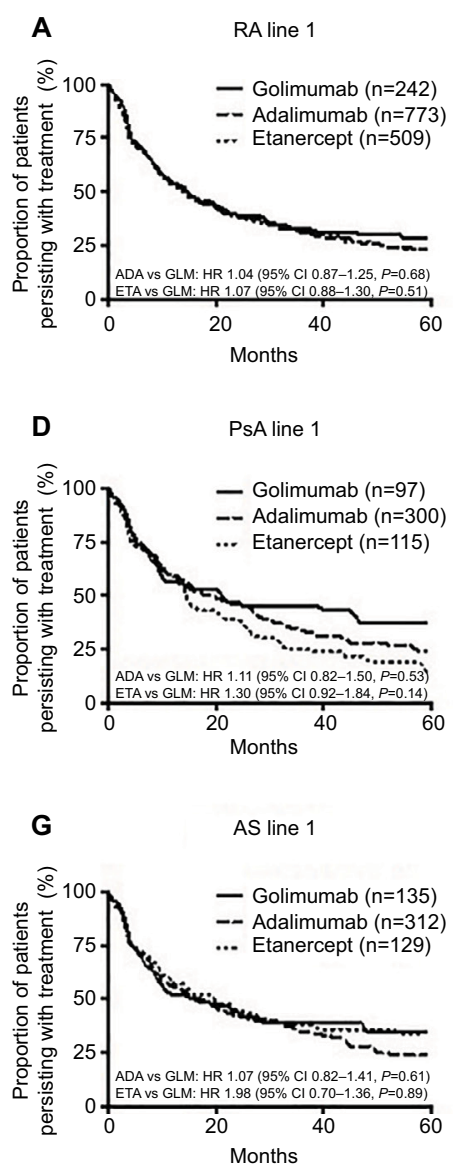
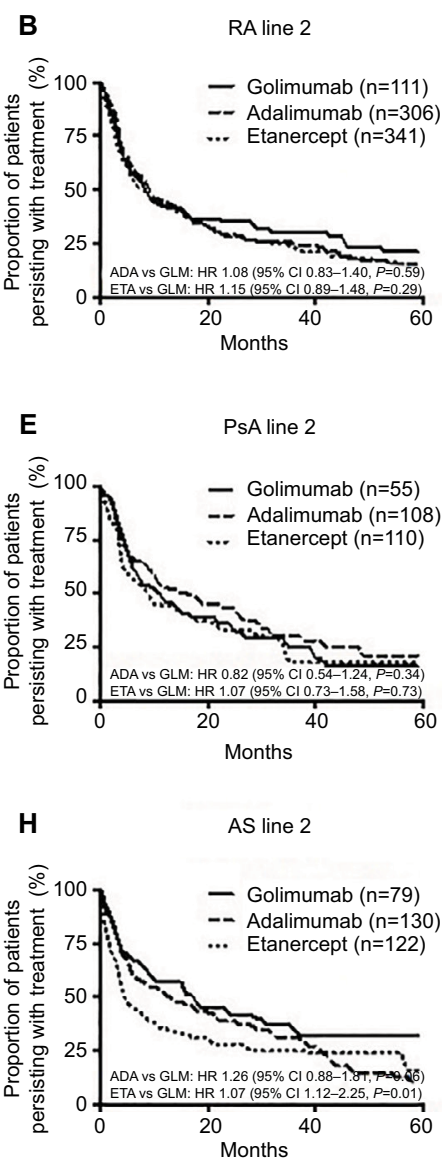
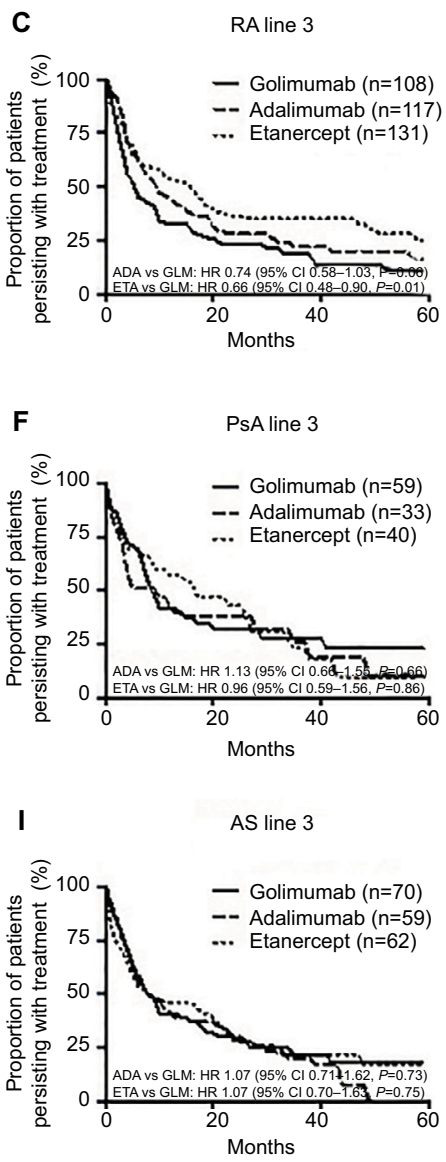

Figure 3 (A-I) Persistence with treatment (months) in unmatched population by treatment, diagnosis, and line of therapy.

(95\% CI 9-19) months (vs adalimumab and vs etanercept, respectively). Treatment persistence with etanercept was significantly shorter than golimumab (HR 1.28, 95\% CI 1.02-1.64, $P=0.03)$. There was no difference in persistence between adalimumab and golimumab (HR 1.12, 95\% CI 0.89-1.41, $P=0.34$; Figure 3). In third and later lines, median treatment persistence with etanercept was longer than with other agents, being adalimumab 10 (95\% CI 8-16) months, etanercept 20 (95\% CI 16-26) months, and golimumab 9 (95\% CI 7-13) or 10 (95\% CI 7-13) months (vs for adalimumab and vs etanercept, respectively). Treatment persistence with etanercept was significantly longer than that with golimumab (HR 0.74, 95\% CI 0.56-0.97, $P=0.03$ ), but there was no difference between adalimumab and golimumab (HR $0.93,95 \%$ CI $0.71-1.22, P=0.59$; Figure 4).

\section{Sensitivity analysis}

A sensitivity analysis was undertaken for first-line treatment to omit patients prescribed golimumab who may have participated in an early access program prior to government reimbursed availability to test for any potential bias introduced by those patients. We found no evidence that the patients who participated in the early access program had any impact on the overall persistence findings (data not shown).

\section{Discussion}

Treatment persistence with golimumab was similar to that of adalimumab for all lines of therapy. For first-line therapy, there was no difference in treatment persistence between golimumab and etanercept, although persistence with etanercept was significantly lower in second-line and higher in third-line. Differences in persistence were consistent in both the overall cohort and in propensity score matched cohorts. Sensitivity analysis, assessing the potential bias introduced by patients accessing golimumab in an early access scheme, found no differences with the overall findings.

Indication specific results found that in the RA cohort, etanercept had significantly higher persistence than golimumab in third-line. In the AS cohort, etanercept had significantly shorter persistence in second-line compared with golimumab. There were no differences between adalimumab and golimumab across all indications and lines of therapy. 

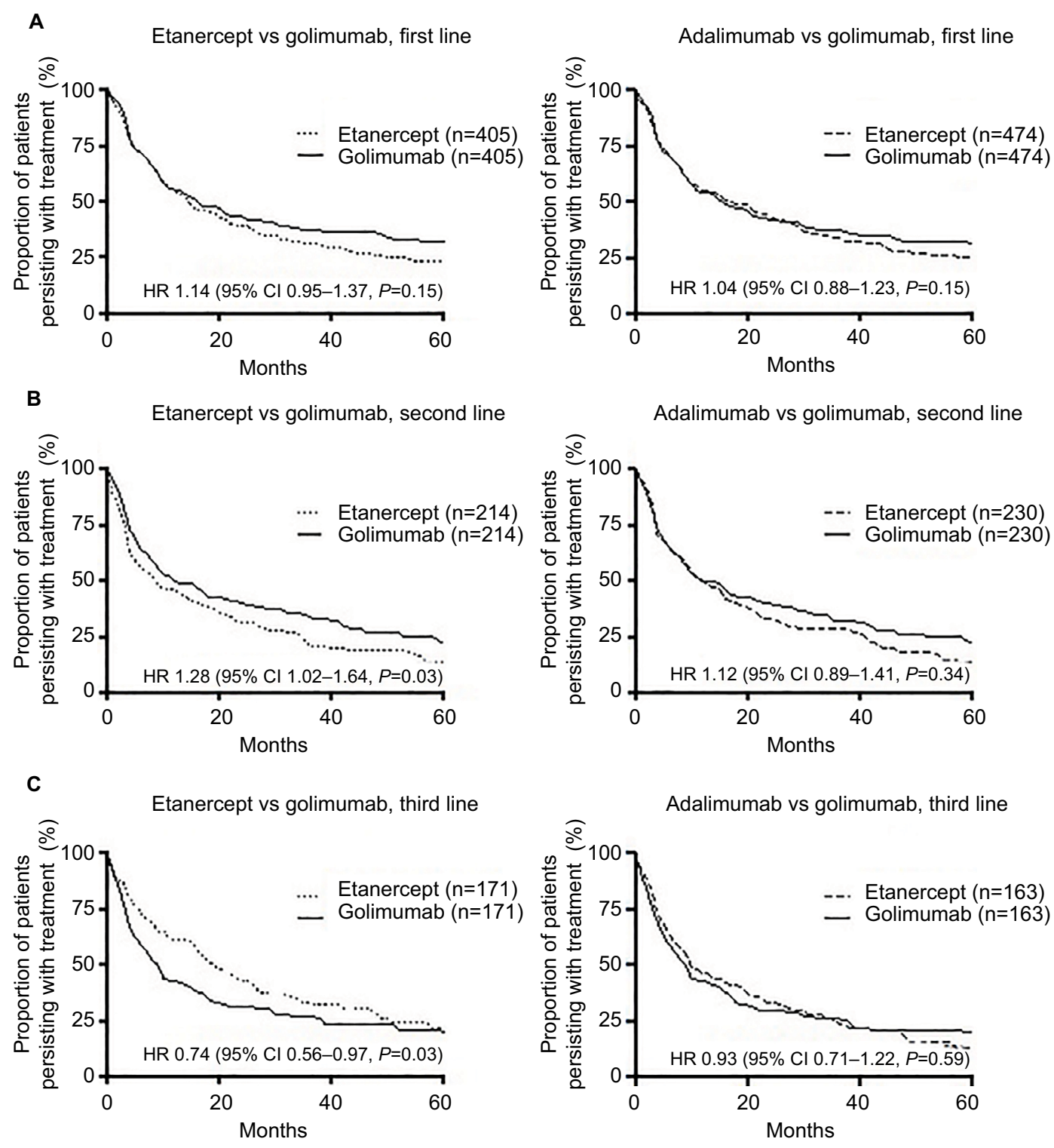

Figure 4 (A-C) Persistence with treatment (months) in propensity score matched populations, by line of therapy.

This study has shown that treatment persistence with TNFi differs by line of therapy, with first-line therapy persistence being significantly higher than that of second-line and third-line therapies. It was observed that, while there were no differences between golimumab and adalimumab across all persistence analyses, there were a disproportionately low proportion of patients prescribed golimumab in the first-line and second-line compared to etanercept and adalimumab, with golimumab making up the majority of third-line prescriptions.

The lack of difference in treatment persistence when comparing by line and similar administration, has recently been reported using a large observational dataset of Australian patients in the Australian Optimizing Patient outcomes in Australian rheumatoLogy (OPAL) registry database. ${ }^{17}$ Another Australian study found TNFi had similar persistence..$^{18}$ In that study, persistence was defined as the time from first dose of the bDMARD until the date of the last dose when there had not been a script dispensed for 6 months, and no propensity score matching was used..$^{18}$ No rationale was provided in this study for choosing the 6-month cutoff. We chose the 3-month cutoff on the basis of evidence that $99 \%$ of patients did not receive subsequent treatment in the 3-6month interval following their last prescription if they had 
not received treatment in the $0-3$-month interval following their last prescription.

Our finding of no difference in treatment persistence contrasts with that suggested by recent Swedish and Canadian reports, which suggested that persistence with golimumab was superior to adalimumab. ${ }^{4,6}$ The Swedish study was similar to our study in that propensity score matching based on age, sex, and disease type was used; however they also included a comorbidity index, co-medications and hospitalization, which may have been surrogate markers for disease severity. We did not assess the effect on persistence of concomitant administration of methotrexate or other cDMARDs because these data are difficult to extract from the PBS dataset given the low cost of these medications, which means they are often not dispensed using a PBS prescription. A Finnish study has also reported no difference in treatment persistence between adalimumab, etanercept, and golimumab. ${ }^{9}$

This study demonstrates that time to TNFi discontinuation is shorter compared to other published registry evidence. A study in France reported first line RA, PsA, and AS anti-TNF overall median at 39 months. ${ }^{19}$ In Canada, median persistence was estimated at 3.3 years and 3.8 years for adalimumab and etanercept, respectively, for all lines of therapy in RA. ${ }^{20}$ In the Netherlands and Britain, TNFi treatments in RA were estimated to have a median persistence time of 3.5 and 3.3 years respectively. ${ }^{21,22}$ In a study of PsA persistence in the US, biologic naïve patients were estimated to have a median of 32 months, and biologic experienced patients had 23 months. ${ }^{23}$ An Australian registry study reported overall median persistence between 24.6 months and 33.6 months across RA, AS, PsA, and undifferentiated arthritis. ${ }^{17}$

Interestingly, a drug claims database analysis in Sweden reported similar median time on therapy to this study, ranging from 15.1 to 18.1 months for RA, PsA, and AS overall. ${ }^{4}$

In the Australian context, the key difference between the OPAL registry data and the PBS drug dispensation data is that registries report time on therapy based on clinician input following patient consultation. The PBS drug dispensation data are a representation of what has actually been dispensed. Therefore, the difference in medians could be attributable to patient non-adherence to prescribed treatments or systemic differences in patient populations.

\section{Limitations}

This study is limited by the low sample sizes, especially in terms of specific indications, which is a consequence of only being able to access a $10 \%$ sample of prescription data. While propensity score matching was undertaken in order to minimize differences between treatment cohorts, data on disease severity was not available within the PBS dataset and therefore inherent differences in disease severity between cohorts and its effect on treatment persistence was not assessed. Finally, the reason for discontinuation is not available in this dataset, so it is unclear whether patients discontinued the therapy due to lack of efficacy, side effects, achieved remission or another reason.

\section{Conclusion}

Our study shows there is variance in real-world persistence to TNFi in patients with IMRDs by line of therapy, with the time on therapy decreasing by line. Australian persistence has been reported at lower overall rates than international evidence. As new treatments become available, it is suggested that this analysis is repeated to understand the persistence of these new therapies. Further research topics could seek to explore how sequencing or pathology might impact persistence, along with the impact of poor persistence to Australian health care costs.

\section{Acknowledgments}

The authors thank Belinda Butcher BSc(Hons) MBiostat PhD CMPP AStat of WriteSource Medical Pty Ltd., Sydney, Australia, for providing medical writing support, which was funded by Janssen-Cilag Pty Ltd., Australia in accordance with Good Publication Practice (GPP3) guidelines (http://www. ismpp.org/gpp3). The abstract of this paper was presented at the Australian Rheumatology Association conference as a poster presentation with interim findings. The poster's abstract was published in Wiley Online Library Abstracts: https://onlinelibrary.wiley.com/doi/abs/10.1111/imj.13426.

\section{Disclosure}

MA and MH are employees of Janssen-Cilag Pty Ltd., who market golimumab (SIMPONI). PJ is an employee of Prospection Pty Ltd. who were contracted by Janssen-Cilag Pty Ltd. to perform the analyses. The authors report no other conflicts of interest in this work.

\section{References}

1. Ramiro S, Landewé R, van der Heijde D, Harrison D, Collier D, Michaud $\mathrm{K}$. Discontinuation rates of biologics in patients with rheumatoid arthritis: are TNF inhibitors different from non-TNF inhibitors? RMD Open. 2015;1(1):e000155.

2. Favalli EG, Raimondo MG, Becciolini A, Crotti C, Biggioggero M, Caporali R. The management of first-line biologic therapy failures in rheumatoid arthritis: Current practice and future perspectives. Autoimmun Rev. 2017;16(12):1185-1195. 
3. Koncz T, Pentek M, Brodszky V, Ersek K, Orlewska E, Gulacsi L. Adherence to biologic DMARD therapies in rheumatoid arthritis. Expert Opin Biol Ther. 2010;10(9):1367-1378.

4. Dalén J, Svedbom A, Black CM, et al. Treatment persistence among patients with immune-mediated rheumatic disease newly treated with subcutaneous TNF-alpha inhibitors and costs associated with nonpersistence. Rheumatol Int. 2016;36(7):987-995.

5. Tkacz J, Ellis L, Bolge SC, Meyer R, Brady BL, Ruetsch C. Utilization and adherence patterns of subcutaneously administered anti-tumor necrosis factor treatment among rheumatoid arthritis patients. Clin Ther. 2014;36(5):737-747.

6. Bhoi P, Bessette L, Bell MJ, Tkaczyk C, Nantel F, Maslova K. Adherence and dosing interval of subcutaneous antitumour necrosis factor biologics among patients with inflammatory arthritis: analysis from a Canadian administrative database. BMJ Open. 2017;7(9):e015872.

7. Meissner B, Trivedi D, You M, Rosenblatt L. Switching of biologic disease modifying anti-rheumatic drugs in patients with rheumatoid arthritis in a real world setting. J Med Econ. 2014;17(4):259-265.

8. Tang B, Rahman M, Waters HC, Callegari P. Treatment persistence with adalimumab, etanercept, or infliximab in combination with methotrexate and the effects on health care costs in patients with rheumatoid arthritis. Clin Ther. 2008;30(7):1375-1384.

9. Aaltonen K, Heinonen A, Joensuu J, et al. Effectiveness and drug survival of TNF-inhibitors in the treatment of psoriatic arthritis: A prospective cohort study. Semin Arthritis Rheum. 2017;46(6):732-739.

10. Fisher A, Bassett K, Wright JM, Brookhart MA, Freeman H, Dormuth CR. Comparative persistence of the TNF antagonists in rheumatoid arthritis--a population-based cohort study. PLoS One. 2014;9(8):e105193.

11. Svedbom A, Storck C, Kachroo S, Govoni M, Khalifa A. Persistence with golimumab in immune-mediated rheumatic diseases: a systematic review of real-world evidence in rheumatoid arthritis, axial spondyloarthritis, and psoriatic arthritis. Patient Prefer Adherence. 2017;11:719-729.

12. Lyu R, Govoni M, Ding Q, et al. AB1091 Treatment Persistence with Subcutaneous Biologic Therapies in Patients with Rheumatoid Arthritis. Ann Rheum Dis. 2014;73(Suppl 2):143-153.

13. Lyu R, Ding Q, Govoni M, Fan T. Treatment persistence with subcutaneous biologic therapies in patients with psoriatic arthritis (Psa). Value Health. 2014;17(7):A384-A385.
14. Mahlich J, Sruamsiri R. Persistence with biologic agents for the treatment of rheumatoid arthritis in Japan. Patient Prefer Adherence. 2016;10:1509-1519.

15. Machado MA, Moura CS, Ferre F, Bernatsky S, Rahme E, Acurcio Fde A. Treatment persistence in patients with rheumatoid arthritis and ankylosing spondylitis. Rev Saude Publica. 2016:50:50.

16. Page E, Kemp-Casey A, Korda R, Banks E. Using Australian Pharmaceutical Benefits Scheme data for pharmacoepidemiological research: challenges and approaches. Public Health Res Pract. 2015;25(4):e2541546.

17. Tymms K, Littlejohn G, Griffiths H, et al. Treatment patterns among patients with rheumatic disease (rheumatoid arthritis (RA), ankylosing spondylitis (AS), psoriatic arthritis (PsA) and undifferentiated arthritis (UnA)) treated with subcutaneous TNF inhibitors. Clin Rheumatol. 2018;37(6):1617-1623.

18. Jones G, Hall S, Bird P, et al. A retrospective review of the persistence on bDMARDs prescribed for the treatment of rheumatoid arthritis in the Australian population. Int J Rheum Dis. 2018;21(8):1581-1590.

19. Brocq O, Roux $\mathrm{CH}$, Albert $\mathrm{C}$, et al. TNFalpha antagonist continuation rates in 442 patients with inflammatory joint disease. Joint Bone Spine. 2007;74(2):148-154.

20. Harrold LR, Stolshek BS, Rebello S, et al. Impact of prior biologic use on persistence of treatment in patients with psoriatic arthritis enrolled in the US Corrona registry. Clin Rheumatol. 2017;36(4):895-901.

21. Kievit W, Fransen J, Adang EM, et al. Long-term effectiveness and safety of TNF-blocking agents in daily clinical practice: results from the Dutch Rheumatoid Arthritis Monitoring register. Rheumatology. 2011;50(1):196-203.

22. Soliman MM, Ashcroft DM, Watson KD, et al. Impact of concomitant use of DMARDs on the persistence with anti-TNF therapies in patients with rheumatoid arthritis: results from the British Society for Rheumatology Biologics Register. Ann Rheum Dis. 2011;70(4):583-589.

23. Feldman SR, Bonafede MM, Pelletier C, et al. Comparison of persistence and adherence in biologic naïve patients with psoriatic arthritis initiating apremilast or biologics in a US administrative claims database. Value Health. 2017;20(9):A541. 


\section{Supplementary material}

Table SI Demographics of propensity matched cohorts

\begin{tabular}{|c|c|c|c|c|}
\hline & Adalimumab & Golimumab & Etanercept & Golimumab \\
\hline First-line & $n=474$ & $n=474$ & $n=405$ & $n=405$ \\
\hline Female, n (\%) & $278(59 \%)$ & $277(58 \%)$ & $250(62 \%)$ & $259(64 \%)$ \\
\hline Age at initiation, years, mean (SD) & $51.7(14.6)$ & $51.7(14.6)$ & $52.2(14.3)$ & $52.9(14.1)$ \\
\hline $\begin{array}{l}\text { State, } \mathrm{n}(\%) \\
\text { Australian Capital Territory/New South Wales } \\
\text { Queensland } \\
\text { South Australia/Northern Territory } \\
\text { Victoria/Tasmania } \\
\text { Western Australia }\end{array}$ & $\begin{array}{l}\text { II } 17(25 \%) \\
86(18 \%) \\
22(5 \%) \\
93(23 \%) \\
94(23 \%)\end{array}$ & $\begin{array}{l}116(29 \%) \\
73(18 \%) \\
24(6 \%) \\
105(26 \%) \\
87(21 \%)\end{array}$ & $\begin{array}{l}\text { II } 4(28 \%) \\
8 \text { I (20\%) } \\
23(6 \%) \\
93(23 \%) \\
94(23 \%)\end{array}$ & $\begin{array}{l}116(29 \%) \\
73(18 \%) \\
24(6 \%) \\
105(26 \%) \\
87(21 \%)\end{array}$ \\
\hline $\begin{array}{l}\text { Indication, } \mathrm{n}(\%) \\
\text { Ankylosing spondylitis } \\
\text { Psoriatic arthritis } \\
\text { Rheumatoid arthritis }\end{array}$ & $\begin{array}{l}81(20 \%) \\
77(19 \%) \\
247(61 \%)\end{array}$ & $\begin{array}{l}82(20 \%) \\
81(20 \%) \\
242(60 \%)\end{array}$ & $\begin{array}{l}81(20 \%) \\
77(19 \%) \\
247(61 \%)\end{array}$ & $\begin{array}{l}82(20 \%) \\
81(20 \%) \\
242(60 \%)\end{array}$ \\
\hline Second-line & $n=230$ & $n=230$ & $n=214$ & $n=214$ \\
\hline Female, $\mathrm{n}(\%)$ & $163(7 \mid \%)$ & 149 (65\%) & $152(7 \mid \%)$ & $142(66 \%)$ \\
\hline Age at initiation, years, mean (SD) & $52.3(15.1)$ & $52.7(14.7)$ & $51.4(14.6)$ & $51.4(14.9)$ \\
\hline $\begin{array}{l}\text { State, } \mathrm{n}(\%) \\
\text { Australian Capital Territory/New South Wales } \\
\text { Queensland } \\
\text { South Australia/Northern Territory } \\
\text { Victoria/Tasmania } \\
\text { Western Australia }\end{array}$ & $\begin{array}{l}55(24 \%) \\
50(22 \%) \\
24(10 \%) \\
52(23 \%) \\
49(21 \%)\end{array}$ & $\begin{array}{l}55(24 \%) \\
50(22 \%) \\
21(9 \%) \\
51(22 \%) \\
53(23 \%)\end{array}$ & $\begin{array}{l}58(27 \%) \\
49(23 \%) \\
18(8 \%) \\
47(22 \%) \\
42(20 \%)\end{array}$ & $\begin{array}{l}55(26 \%) \\
48(22 \%) \\
17(8 \%) \\
51(24 \%) \\
43(20 \%)\end{array}$ \\
\hline $\begin{array}{l}\text { Indication, } \mathrm{n}(\%) \\
\text { Ankylosing spondylitis } \\
\text { Psoriatic arthritis } \\
\text { Rheumatoid arthritis }\end{array}$ & $\begin{array}{l}67(29 \%) \\
55(24 \%) \\
108(47 \%)\end{array}$ & $\begin{array}{l}70(30 \%) \\
56(24 \%) \\
104(45 \%)\end{array}$ & $\begin{array}{l}58(27 \%) \\
51(24 \%) \\
105(49 \%)\end{array}$ & $\begin{array}{l}54(25 \%) \\
56(26 \%) \\
104(49 \%)\end{array}$ \\
\hline Third-line & $n=163$ & $n=163$ & $n=|7|$ & $n=|7|$ \\
\hline Female, $\mathrm{n}(\%)$ & $104(64 \%)$ & $108(66 \%)$ & $\mid 22(7 \mid \%)$ & $123(72 \%)$ \\
\hline Age at initiation, years, mean (SD) & $51.9(14.2 \%)$ & $53.1(14.1)$ & $53.0(14.5)$ & $53.6(14.0)$ \\
\hline $\begin{array}{l}\text { State, } \mathrm{n}(\%) \\
\text { Australian Capital Territory/New South Wales } \\
\text { Queensland } \\
\text { South Australia/Northern Territory } \\
\text { Victoria/Tasmania } \\
\text { Western Australia } \\
\text { Missing }\end{array}$ & $\begin{array}{l}4 I(25 \%) \\
31(19 \%) \\
8(5 \%) \\
33(20 \%) \\
49(30 \%) \\
1(1 \%)\end{array}$ & $\begin{array}{l}49(30 \%) \\
27(17 \%) \\
5(3 \%) \\
33(20 \%) \\
48(29 \%) \\
1(1 \%)\end{array}$ & $\begin{array}{l}47(27 \%) \\
28(16 \%) \\
9(5 \%) \\
44(26 \%) \\
43(25 \%) \\
-\end{array}$ & $\begin{array}{l}52(30 \%) \\
25(15 \%) \\
10(6 \%) \\
40(23 \%) \\
43(25 \%) \\
1(1 \%)\end{array}$ \\
\hline $\begin{array}{l}\text { Indication, } \mathrm{n}(\%) \\
\text { Ankylosing spondylitis } \\
\text { Psoriatic arthritis } \\
\text { Rheumatoid arthritis }\end{array}$ & $\begin{array}{l}47(29 \%) \\
31(19 \%) \\
85(52 \%)\end{array}$ & $\begin{array}{l}44(27 \%) \\
31(19 \%) \\
88(54 \%)\end{array}$ & $\begin{array}{l}50(29 \%) \\
37(22 \%) \\
84(49 \%)\end{array}$ & $\begin{array}{l}47(27 \%) \\
32(19 \%) \\
92(54 \%)\end{array}$ \\
\hline
\end{tabular}

Note: There were no significant differences between groups (adalimumab vs golimumab or etanercept vs golimumab) in any baseline characteristics.

Open Access Rheumatology: Research and Reviews

\section{Publish your work in this journal}

Open Access Rheumatology: Research and Reviews is an international, peerreviewed, open access journal publishing original research, reports, editorials, reviews and commentaries on all aspects of clinical and experimental rheumatology in the clinic and laboratory including the following topics: Pathology, pathophysiology of rheumatological diseases; Investigation, treatment and

\section{Dovepress}

management of rheumatological diseases; Clinical trials and novel pharmacologi$\mathrm{cal}$ approaches for the treatment of rheumatological disorders. The manuscript management system is completely online and includes a very quick and fair peer-review system, which is all easy to use. Visit http://www.dovepress.com testimonials.php to read real quotes from published authors. 